\title{
La dinámica salarios-productividad y el desarrollo económico en El Salvador
}

\section{Introducción}

Este artículo aborda un tema que ya se le dio un primer tratamiento en un estudio previo que se publicó en ECA'; en esa ocasión se analizó el problema de la relación entre el comportamiento del salario y la productividad en El Salvador en un período no muy largo (entre 1980-1993), sin embargo, el estudio fue útil para deducir algunas hipótesis acerca del modo en que se relacionaban las dos variables en cuestión. Estas hipótesis se transformaron en las líneas de trabajo de la investigación titulada "El efecto de la dinámica salarios-productividad en el desarrollo económico. Caso El Salvador (1974-1995)"'. Son precisamente los resultados de este estudio que abarca un lapso de 20 años, los cuales se resumirán en este trabajo, pero, además, se revisa la información obtenida acerca del comportamiento de los salarios y la productividad de la década de los 90 's. Las hipótesis que animaron la investigación mencionada se pueden condensar en una sola: el salario real determina el comportamiento de la productividad cuando su magnitud se encuentra por debajo del valor de la fuerza de trabajo. La comprobación de esta hipótesis que se deduce del comportamiento de ambas variables en la economía salvadoreña permite comprobar la hipótesis más general que afirma que el salario real es determinante con respecto a la productividad cuando su magnitud difiere del valor de la fuerza de trabajo. Los resultados a los que conduce esta forma de analizar la relación entre los salarios reales y la productividad rompen con los esquemas teóricos tradicionales tanto en su aspecto explicativo de la economía como en lo referente a la política económica.

La hipótesis se verifica a través de dos vías: probando su consistencia teórica y haciendo la comprobación empírica. En concordancia con esto el artículo se dividirá en cuatro apartados: antecedentes, la formulación teórica, la evidencia empírica y las conclusiones y recomendaciones. 


\section{Antecedentes.}

Si bien el comportamiento de la productividad es un aspecto de importancia vital para el crecimiento y desarrollo económico, generalmente su problemática en cuanto a su crecimiento o decrecimiento se aborda considerando los parámetros relativos a los recursos no humanos, a pesar de que es evidente que la fuerza de trabajo es uno de los principales factores determinantes, si no el principal.

Hace ya más de un siglo que lo anterior fue reconocido por Alfred Marshall: "Tenemos que considerar ahora las condiciones de que dependen la salud y la fuerza física, intelectual y moral. Estas son la base de la eficiencia industrial, de que depende la producción de la riqueza material... la eficiencia industrial requiere casi exclusivamente vigor físico, es decir, fuerza muscular, una buena constitución y hábitos enérgicos"

Aunque este reconocimiento de Marshall fue argumentado con las investigaciones realizadas por economistas como Smith, Ricardo, Malthus, etc. pareciera que ha sido obviada tanto por empresarios como por los encargados de la política económica. Las consecuencias de tal omisión en la economía especialmente de los países subdesarrollados han sido verdaderamente perjudiciales tanto para los trabajadores los cuales han sido directamente afectados como para los empresarios y en general para el desarrollo económico de un país. Semejante omisión significa que muchas de las inversiones realizadas en la economía no son las mejores porque "El más valioso de todos los capitales es el que se invierte en los seres humanos...".

Tomando en cuenta lo anterior y considerando que los salarios constituyen la principal fuente de formación de la calidad del trabajo se examinaron los datos de la productividad y los salarios reales. Esta exploración debía ser de carácter estructural pues si sólo se tomaba un sector de la economía o la economía en su conjunto se corría el riesgo de extender los resultados de un sector a toda la economía en el primer caso, o bien, atribuir el comportamiento de la economía agregada a los distintos sectores que la conforman, en el segundo. De esta manera se estudiaron los datos de la economía total, el sector no agropecuario, el sector agropecuario, la manufactura, la maquila, el café, el algodón y la caña de azúcar. Como era de esperarse entre unos sectores y otros se mostraban diferencias especialmente si se comparaban las variables en estudio por separado, no obstante, al observar el comportamiento interrelacionado de la productividad y los salarios reales de todos los sectores se llegaba a una sola conclusión: la existencia de una correlación entre las dos variables.

En este artículo, por razones obvias de espacio, no pueden presentarse todos los resultados pero hecha la salvedad anterior con relación a lo observado en los distintos sectores, bastará con mostrar los datos de la economía global que se presentan en el gráfico siguiente: 


\section{GRAFICO 1}

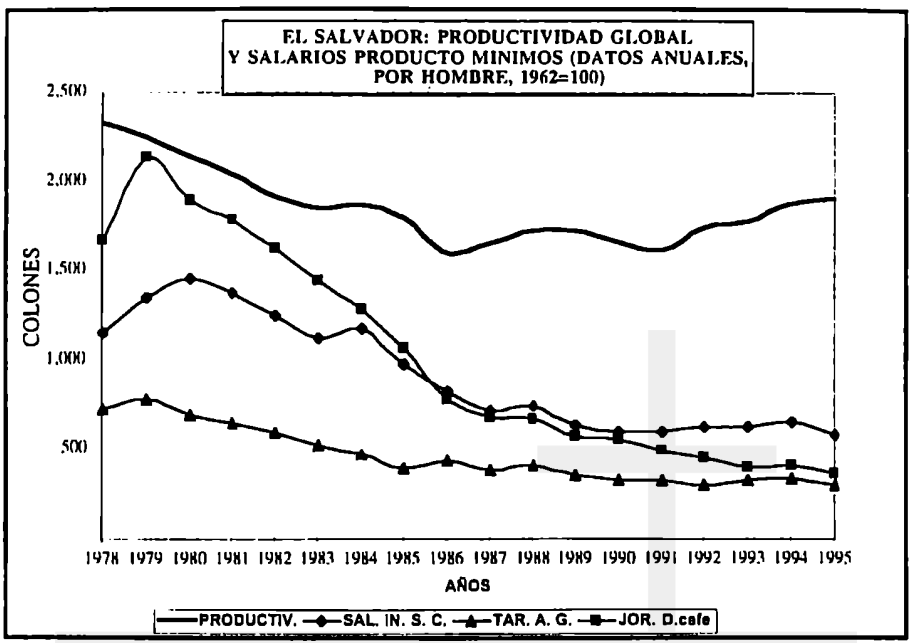

Fuente: elaboración propia en base a datos del MIPLAN y el Banco Central de Reserva (BCR) varios números.

Simbologia: PRODUCTIV.: productividad por trabajador. SAL. IN. S. C.: salarios de la industria, servicios y comercio. TAR. A. G.: tarifa agropecuaria general. JOR. D. café: jornal diario del café.

Dos tendencias se pueden destacar del movimiento de las dos variables: por una parte se puede ver el declinante comportamiento de los salarios reales a lo largo del período entre 1978-1995. Tanto en la industria, servicio y comercio como en la agricultura. Por otro lado, la productividad como variable que se asocia al producto muestra un comportamiento cíclico con tendencia al declive. Aunque esta tendencia a la disminución de ambas variables no fue un patrón que se reflejó en todos los sectores, si pudo determinarse en todos la existencia de una relación entre ellas que debía investigarse. De este estudio preliminar se desprendió la hipótesis central que empezó por verificarse a través de la formulación de una teoría que se explica en términos generales en el apartado que sigue.

\section{Formulación de la teoría.}

El reconocimiento de economistas como Smith, Ricardo y Marshall de la importancia fundamental de la fuerza de trabajo los llevó a investigar la manera de restablecer las condiciones de ésta cuando se somete a los rigores del trabajo. Marshall no sólo retomó las enseñanzas de sus dos predecesores sino que precisó de una manera más clara las condiciones que una fuerza laboral sana y eficiente debe tener. "Con respecto al trabajo muscular en particular, existe una 
intima relación entre la cantidad de alimentos que un hombre posee y sus fuerzas disponibles... Después de los alimentos, las cosas necesarias para la vida y para el trabajo son el vestido, la habitación y la calefacción. Cuando éstas son deficientes, la mente se entorpece $y$, a la postre, la constitución física queda minada... El descanso también es esencial para que la población sea vigorosa, lo mismo que las cosas materiales necesarias para la vida, como los alimentos, vestidos, etc."s.

Sin embargo, aunque Marshall al igual que sus antecesores vislumbraron la importancia de la mano de obra en el impulso del desarrollo de una nación, sus ideas confusas en cuanto al "trabajo" y al pago o "ganancias del trabajo" no les permitieron estudiar las consecuencias de una fuerza laboral que no logra cubrir el desgaste que sufre en sus labores productivas que realiza para el empresario, esto es, para el capitalista; difícilmente hubiesen podido llegar a ello cuando confundían el salario del obrero con la ganancia y el capital con la actividad laboral'. Sólo las investigaciones de Marx permiten comprender con precisión el proceso de influencia de la capacidad de trabajo sobre la eficiencia gracias a la categoría clave de valor de la fuerza de trabajo, el presente estudio aborda dicho proceso.

En este apartado se hará un planteamiento teórico bastante mecánico ${ }^{7}$, en la práctica las relaciones entre las variables que se vinculan, como se comprobará en la evidencia empírica, no son tan simples, no obstante, el esquema teórico servirá para presentar lo más relevante en las relaciones que se establecen entre los salarios reales, valor de la fuerza de trabajo, la productividad, la tecnología, los tipos de beneficio, etc.

Por lo tanto, antes de pasar a la explicación de la teoría es necesario definir la simbología que se utilizarán en los esquemas que apoyan el planteamiento teórico:

1) Salario real (SR).

2) Valor de la fuerza de trabajo (VFT).

3) Calidad normal de la fuerza de trabajo (CNFT).

4) Pleno aprovechamiento de la tecnología (PAT).

5) Productividad (p).

6) Desarrollo económico (DE).

7) Alimentación, salud, educación y diversión (ASED).

Una vez establecida la simbología pertinente que se utilizará en los diagramas se puede formular la teoría en los términos siguientes:

El valor de la fuerza de trabajo no es un coeficiente técnico, es más bien un parámetro y una variable socioeconómica de difícil conocimiento y apreciación por parte de las empresas capitalistas enfrascadas en reducirlo al mínimo para elevar la plusvalía; este valor de la fuerza de trabajo, que los obreros sí conocen muy bien, depende de: 
1. Los bienes de manutención básicos, los cuales no se hallan fijados de una vez y para siempre.

2. Las necesidades sociales, morales y de carácter histórico (Ver Marx, C. El capital).

En un momento dado el valor de la fuerza de trabajo (VFT) es un parámetro que debe ser cubierto por el salario real ${ }^{4}$ (SR) para que se alcance una calidad normal en la capacidad laboral (CNFT) de tal manera que los avances científicotécnicos puedan ser aprovechados (PAT) permitiendo el crecimiento y desarrollo de la economía capitalista (DE); pero al ocurrir esto el valor de la fuerza de trabajo crece, de modo que otro tanto debe darse con el salario real; el progreso científico y la capacidad del trabajador son aprovechados aún más elevándose la productividad (p) y el desarrollo económico (ver diagrama 1). La plusvalía en este proceso crece junto a la productividad que aumenta más rápido que los salarios reales"'.

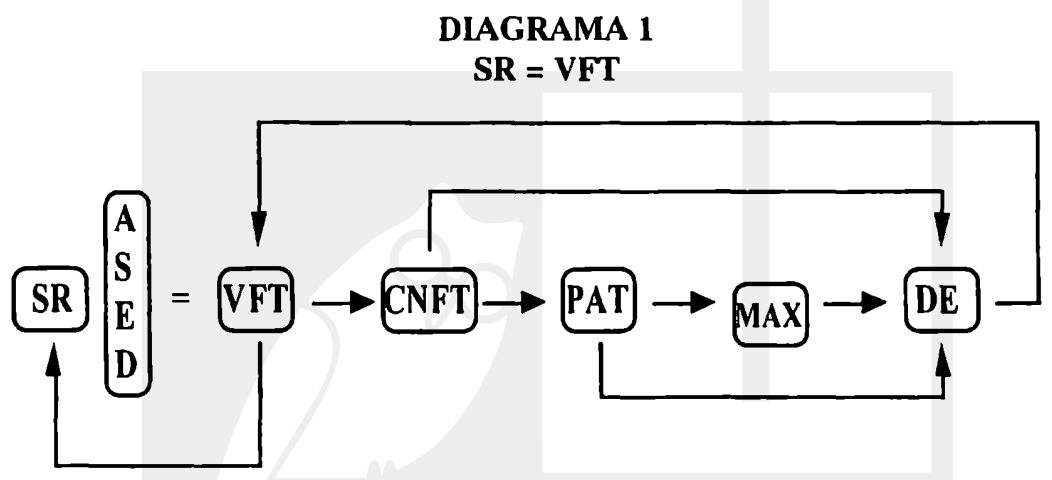

SR: Salario Real; ASED: Alimentación y otras Necesidades Básicas, Salud, Educación, Diversión; VFT: Valor de la Fucrza de Trabajo; CNFT: Calidad Normal de la Fucrza de Trabajo; PAT: Pleno Aprovechamiento de la Tecnología; p: Productividad; DE: Desarrollo Económico.

Marx encuentra, en base a las leyes económicas que operan en el capitalismo descubiertas por él, que este proceso se desenvuelve de forma caótica y discontinua, sin embargo, este estudio solamente dirigirá la atención a estos aspectos importantes del marxismo en la medida en que tengan relación con lo que se quiere demostrar, ello, obviamente, para facilitar su comprensión.

Ahora bien, si debido al afán de lucro del capitalista y a su éxito en imponerse sobre los intereses económicos de los trabajadores, logra fijar un salario inferior al valor de la fuerza de trabajo $(\mathrm{SR}<\mathrm{VFT})$; la capacidad productiva de los obreros (CNFT) comienza a disminuir y, por lo tanto, los avances técnicos que 
se han alcanzado no son aprovechados plenamente (PAT); las razones de semejante situación se señalan a continuación:

a) El deterioro de las condiciones nutricionales, que provoca dos cosas importantes: una, el debilitamiento de la salud física del obrero (y sus descendientes), dos, el surgimiento prematuro de la fatiga; ambos fenómenos merman la eficiencia del obrero.

b) El deterioro psicosocial que se refleja en problemas del sistema nervioso y en la reducción del nivel educacional, lo que disminuye la capacidad de aprovechamiento de los programas de capacitación laboral y por ende de las tecnologías.

El impacto de este deterioro de la capacidad productiva del obrero se experimenta, en un principio, en el aumento de los gastos de trabajo, lo que a este nivel no hace caer la productividad (p) pero frena su crecimiento. Luego si al transcurrir el tiempo los salarios (SR) se estancan o decrecen, lo cual quiere decir que se sigue ubicando por debajo del valor de la fuerza de trabajo (VFT), la disminución de la capacidad productiva (CNFT) termina por hacer caer la productividad (p); los gastos de trabajo se vuelven cada vez más altos debido a la necesidad de hacer frente a las interrupciones en el trabajo por los problemas de salud, por la pérdida de habilidades y destrezas, y del nivel de captación en los programas de capacitación para el manejo de nuevas tecnologías. Al mantenerse los gastos de trabajo creciendo, la productividad finalmente cae, el desarrollo económico se estanca y luego se reduce (o se empeora el sub-desarrollo", $\mathrm{SDE})$, se destruye la mano de obra y se desaprovecha la ciencia y la tecnología (PAT). De esta forma se ha entorpecido la cadena de interacciones óptimas (lo que se simboliza con $\Delta$, ver diagrama 2 ).

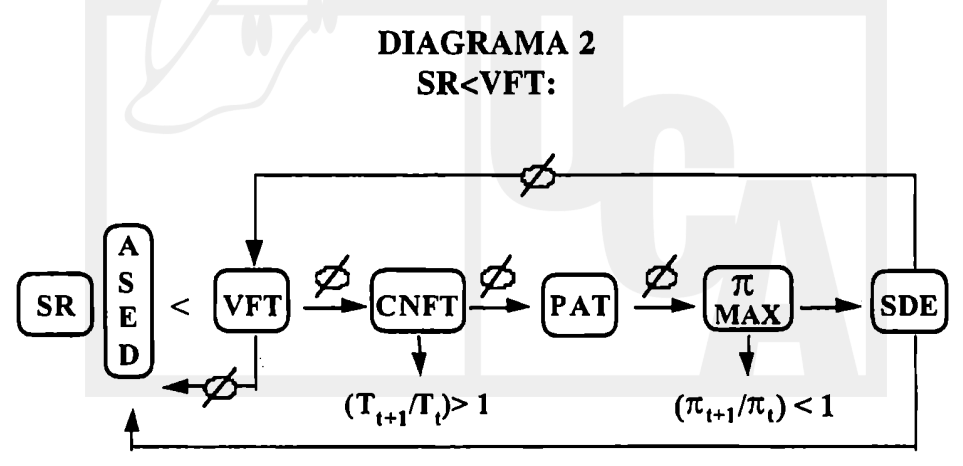

SR: Salario Real; ASED: Alimentación y otras Necesidades Básicas, Salud, Educación, Diversión; VFT: Valor de la Fuerza de Trabajo; CNFT: Calidad Normal de la Fuerza de Trabajo; PAT: Pleno Aprovechamiento de la Tecnología; p: Productividad; SDE: Sub-Desarrollo Económico. 
Si el salario real sigue cayendo o se estanca, la productividad puede decrecer más rápido que el salario real y en ese caso la tasa de plusvalía disminuiría; y si la composición orgánica del capital permanece constante, también se reduciría la tasa de ganancia, en este momento el capitalismo está a las puertas de una crisis económica. Esta situación puede ser asimismo el resultado de otros factores que, como se comprenderá, únicamente agudizan el perjuicio originado por la caída secular de los salarios reales por debajo del valor de la fuerza de trabajo $(\mathrm{SR}<\mathrm{VFT})$.

Cuando la situación productiva se halla en tales condiciones, la tecnología no es aprovechada plenamente; para poder lograrlo se hace necesario que los salarios reales aumenten para que la productividad se reanime y con ella la plusvalía y la tasa de ganancia ${ }^{12}$.

Pero hay que advertir que no se puede esperar un efecto instantáneo entre el aumento del salario real y los incrementos de la productividad; en primer lugar, al crecer el salario real el decrecimiento de la productividad empezaría a revertirse por la mejora en el nivel de vida del obrero; si el salario siguiera creciendo hasta cubrir el valor de la fuerza de trabajo la productividad terminaría por crecer también, de aquí en adelante el valor de la fuerza de trabajo, y por tanto el salario real, comenzaría a "seguir" los incrementos de la productividad, los cuales, de acuerdo con la teoría marxista, tenderían a ser siempre superiores a los ritmos de crecimiento del salario, de modo que se asegure que la tasa de explotación también se esté incrementando. Es claro, y es bueno señalarlo, que el marxismo no se desploma por el hecho de que se corrobore que los ritmos de crecimiento entre el salario real y la productividad sean los mismos, tal y como supone el equilibrio neoclásico. La teoría de Marx, hasta aceptando esa estabilidad en la tasa de explotación, puede explicar la manera en que la tasa de ganancia de los capitalistas puede aumentar, o bien, disminuir metiendo al sistema en una crisis.

Se puede argumentar que todo este fenómeno, en condiciones de fácil sustituibilidad de la mano de obra, como comprueba Dierckxsens que ocurre en casi todos los países de la región centroamericana ${ }^{13}$, no sucedería pues los capitalistas podrían sustituir rápidamente la fuerza de trabajo; Marx también menciona esto (El capital T. I. 1980. Capítulo X: La jomada de trabajo). No obstante, aunque no hay duda de que tal cosa es posible, ello supone que los capitalistas poseen un conocimiento perfecto para anticipar el momento en que el rendimiento de los trabajadores va disminuir debido a que sus salarios no cubren el valor de la fuerza de trabajo. Parece más sensato suponer que solamente ex-post, una vez que los capitalistas experimentan merma en la productividad y en sus ganancias, deciden cambiar el personal ineficiente. Sin embargo, aquí la evidencia empírica es la que tiene la última palabra, para lo cual se dedicará el siguiente apartado. 


\section{La evidencia empírica.}

En esta parte se presenta la verificación de la hipótesis central; sin embargo es necesario señalar que su comprobación tiene que estar respaldada por la reducción al mínimo de la posibilidad que el comportamiento observado en la productividad no tenga que ver con los cambios que sufren otras variables (aparte del salario real) también de importancia y que deben encontrarse bajo el control de la investigación, a manera de evitar que sus influencias al no ser tenidas en cuenta puedan hacer espuria la vinculación constatada entre los salarios reales y la productividad. Para ello en los datos utilizados para la verificación se incluyen otras variables que se consideran importantes en relación con el comportamiento de la productividad tales como: el coeficiente capital-trabajo, como indicador de la tecnología, la guerra, la intensidad del trabajo y el PIB, este último como indicador de la demanda agregada.

\subsection{Valor de la fuerza de trabajo y salarios.}

La medición del valor de la fuerza de trabajo en El Salvador no es una tarea sencilla, dado que el mercado de trabajo realmente se encuentra diferenciado y aunque se puede llegar al establecimiento de un valor energético necesario para la conservación fisiológica del ser humano, se torna por otro lado muy difícil tratar de determinar el gasto que las familias de los trabajadores requieren para cubrir el valor de la parte correspondiente a los aspectos de carácter moral, histórico-social y psicológico. Sin embargo, es de suponer que en un país tan pequeño con redes de comunicación y medios de transporte considerables y con la totalidad de las poblaciones muy cercanas a los principales centros urbanos del país, no debe presentar abismales diferencias entre las necesidades de los trabajadores de las áreas rurales y las de los trabajadores de los centros urbanos.

Aun teniendo en cuenta la similitud que puede existir entre el valor de la fuerza de trabajo de las zonas rurales y urbanas, se ha creído conveniente tomar como indicadores del valor de la fuerza de trabajo (en términos monetarios) tres tipos de canastas básicas:

1. La canasta de mercado promedio la cual es representativa de la población urbana del país, y es obtenida como un promedio del consumo de la población. Para la metodología de su cálculo se compone de los siguientes subgrupos: los alimentos, vivienda, vestuario y misceláneos. Esta canasta de bienes es la que se utiliza la DIGESTYC para el cálculo del índice de precios al consumidor (IPC).

2. La canasta alimenticia promedio que se calcula a partir del subgrupo de alimentos contenida en la canasta de mercado promedio.

3. La canasta básica alimentaria (CBA) que era calculada por el Ministerio de Planificación (MIPLAN) y que hoy es obtenida por la DIGESTYC; 
consiste en la dieta usual de la familia salvadoreña para cubrir las necesidades energéticas de sus miembros.

Existe un relevante defecto de utilizar las canastas básicas como indicadores del valor de la fuerza de trabajo, y es el hecho de que al ser el resultado de encuestas nada asegura que realmente reflejen los hábitos de consumo necesitados por los trabajadores sino aquellos a los que se han adaptado debido a los bajos salarios y a los mecanismos compulsivos del sistema capitalista. Por esa razón la canasta promedio de mercado representa uno de los mejores indicadores ya que incluye todos los niveles de ingreso de la población, desembocando en una canasta de bienes y servicios a la que cualquier trabajador, cuyos ingresos salariales sólo le permiten acceder a una canasta inferior, desearía aproximarse para participar del progreso económico alcanzado por el país.

En lo referente al salario debido a que entre 1975 y 1995 solamente se poseen series de tiempo del salario medio de la industria, se ha hecho necesario utilizar la información sobre salarios mínimos en los demás sectores. Sin embargo, esto no se aleja mucho de la realidad dado que al comparar la información acerca de salarios medios de periodos cortos que se posee con los salarios mínimos se logra constatar que ambos indicadores se hallan muy cercanos y, lo que es más importante, muestran las mismas tendencias. El propio salario medio de la industria manufacturera presenta niveles y tendencias similares a la del salario mínimo de la industria comercio y servicios ${ }^{14}$. Todo esto también se verifica al observar los datos correspondientes a la década de los noventa.

Teniendo presente que la canasta promedio de mercado y la canasta alimenticia de mercado son las mejores aproximaciones (entre las que existen) al valor de la fuerza de trabajo y tomando los salarios medios de la industria y, en los sectores para los que no hay salarios medios, los salarios mínimos, se puede establecer un indicador para poder determinar el grado de cobertura que posee el salario mínimo y medio de la manufactura sobre la canasta promedio de mercado; el cual se calcula dividiendo el salario nominal entre la canasta de mercado y luego el resultado se multiplica por cien. En la tabla siguiente se muestran los resultados de ese cálculo.

En el cuadro, puede verse que en 1979 solamente el jornal del café cubría con creces la canasta promedio de mercado (compraba este salario una canasta y el $27.3 \%$ de otra igual), debe recordarse, empero, que el salario del café solamente se da por temporadas. El salario medio de la manufactura cubría el $\mathbf{9 2 . 4 \%}$ de la misma. Por su parte, la tarifa agropecuaria general no alcanzaba ni a comprar la mitad de la canasta de mercado.

Para 1995 la situación era aún más difícil; si se toma en cuenta que la familia promedio se compone de entre 5 y 6 miembros, en el sector agropecuario aunque trabajasen todos no lograrían comprar una canasta de mercado completa, 


\section{Cuadro 1}

Cobertura de los salarios medios (manufactura) y mínimos de la canasta de mercado promedio (CMP)

\begin{tabular}{rrrccc}
\hline Años & SM/CMP & SICS/CMP & TGA/CMP & SCAF/CMP & SAZU/CMP \\
\hline 1979 & $92.4 \%$ & $80.4 \%$ & $46.5 \%$ & $127.3 \%$ & $80.4 \%$ \\
1980 & $112.2 \%$ & $83.7 \%$ & $39.6 \%$ & $108.5 \%$ & $87.5 \%$ \\
1981 & $107.2 \%$ & $72.9 \%$ & $34.5 \%$ & $94.5 \%$ & $76.2 \%$ \\
1982 & $97.8 \%$ & $65.3 \%$ & $30.9 \%$ & $84.6 \%$ & $68.2 \%$ \\
1983 & $93.9 \%$ & $57.7 \%$ & $27.3 \%$ & $74.8 \%$ & $60.3 \%$ \\
1984 & $88.8 \%$ & $61.1 \%$ & $24.4 \%$ & $66.9 \%$ & $54.0 \%$ \\
1985 & $78.1 \%$ & $49.9 \%$ & $20.0 \%$ & $54.7 \%$ & $44.2 \%$ \\
1986 & $59.8 \%$ & $43.7 \%$ & $23.3 \%$ & $41.5 \%$ & $33.5 \%$ \\
1987 & $48.1 \%$ & $35.0 \%$ & $18.6 \%$ & $33.2 \%$ & $26.8 \%$ \\
1988 & $40.2 \%$ & $35.0 \%$ & $19.5 \%$ & $31.6 \%$ & $26.3 \%$ \\
1989 & $34.0 \%$ & $29.8 \%$ & $16.5 \%$ & $26.9 \%$ & $22.3 \%$ \\
1990 & $36.1 \%$ & $28.0 \%$ & $15.3 \%$ & $26.0 \%$ & $21.6 \%$ \\
1991 & $31.5 \%$ & $27.4 \%$ & $15.2 \%$ & $22.7 \%$ & $18.9 \%$ \\
1992 & $28.9 \%$ & $28.3 \%$ & $13.6 \%$ & $20.4 \%$ & $17.0 \%$ \\
1993 & $24.7 \%$ & $27.4 \%$ & $14.2 \%$ & $17.3 \%$ & $14.3 \%$ \\
1994 & nd & $28.0 \%$ & $14.4 \%$ & $17.2 \%$ & $14.6 \%$ \\
1995 & nd & $26.1 \%$ & $13.4 \%$ & $16.0 \%$ & $13.6 \%$ \\
\hline
\end{tabular}

Fuente: EXMIPLAN, BCR Y SECONAN.

Siglas: Salario medio de manufactura (SM). Salario de la industria, comercio y scrvicio (SICS). Tarifa general agropecuaria (TAG). Jornal del café (SCAF). Jornal de la caña de azúcar (SAZU). (Cuadro 5 de la tesis).

mientras en la industria deberían trabajar de 3 a 4 miembros para poder obtener el conjunto de bienes que contiene la canasta de mercado. Si se toman los salarios medios de 1993 la situación es parecida.

Al comparar los salarios medios y mínimos con la canasta alimenticia promedio, comprobamos que en 1979 era posible comprar más de una canasta de alimentos bastante variados, pero para 1995 era necesario en el agro que trabajaran tres personas y en la ciudad dos para poder obtener la misma canasta de alimentos diversos (ver cuadro 2).

Si se acepta que el valor de la fuerza de trabajo se encuentra próximo a la canasta promedio de mercado, se estaría ante una situación en la cual la fuerza de trabajo no se remunera a su valor. Considérese en el cuadro que sigue el indicador de cobertura para la canasta básica alimenticia del MIPLAN (calculado hoy por la DIGESTYC). 


\section{Cuadro 2}

Cobertura de los salarios medios (manufactura)

y mínimos de la canasta alimenticia promedio (CAP)

\begin{tabular}{|c|c|c|c|c|c|}
\hline AÑOS & SM/CAP & SICS/CAP & TGA/CAP & SCAF/CAP & SAZU/CAP \\
\hline 1979 & $290.0 \%$ & $252.4 \%$ & $145.8 \%$ & $399.6 \%$ & $252.4 \%$ \\
\hline 1980 & $345.6 \%$ & $257.8 \%$ & $121.9 \%$ & $334.0 \%$ & $269.5 \%$ \\
\hline 1981 & $322.1 \%$ & $219.1 \%$ & $103.6 \%$ & $283.8 \%$ & $229.1 \%$ \\
\hline 1982 & $296.7 \%$ & $198.0 \%$ & $93.6 \%$ & $256.5 \%$ & $207.0 \%$ \\
\hline 1983 & $284.3 \%$ & $174.6 \%$ & $82.6 \%$ & $226.2 \%$ & $182.6 \%$ \\
\hline 1984 & $263.1 \%$ & $180.8 \%$ & $72.3 \%$ & $198.2 \%$ & $160.0 \%$ \\
\hline 1985 & $237.9 \%$ & $152.1 \%$ & $60.8 \%$ & $166.7 \%$ & $134.6 \%$ \\
\hline 1986 & $182.3 \%$ & $133.1 \%$ & $71.0 \%$ & $126.5 \%$ & $102.1 \%$ \\
\hline 1987 & $146.3 \%$ & $106.3 \%$ & $56.7 \%$ & $101.0 \%$ & $81.5 \%$ \\
\hline 1988 & $113.1 \%$ & $98.5 \%$ & $54.7 \%$ & $88.9 \%$ & $73.9 \%$ \\
\hline 1989 & $88.5 \%$ & $77.6 \%$ & $43.1 \%$ & $70.0 \%$ & $58.2 \%$ \\
\hline 1990 & $92.6 \%$ & $71.9 \%$ & $39.4 \%$ & $66.8 \%$ & $55.5 \%$ \\
\hline 1991 & $78.4 \%$ & $68.3 \%$ & $37.8 \%$ & $56.7 \%$ & $47.1 \%$ \\
\hline 1992 & $71.0 \%$ & $69.6 \%$ & $33.5 \%$ & $50.2 \%$ & $41.7 \%$ \\
\hline 1993 & $57.3 \%$ & $63.5 \%$ & $32.8 \%$ & $40.0 \%$ & $33.2 \%$ \\
\hline 1994 & Nd & $62.0 \%$ & $31.9 \%$ & $38.1 \%$ & $32.2 \%$ \\
\hline 1995 & Nd & $59.5 \%$ & $30.6 \%$ & $36.5 \%$ & $30.9 \%$ \\
\hline
\end{tabular}

Fuente: cuadros 3 y 4 de la tesis.

Siglas: Salario medio de manufactura (SM). Salario de la industria, comercio y servicio (SICS). Tarifa general agropecuaria (TAG). Jornal del café (SCAF). Jornal de la caña de azúcar (SAZU).

En El Salvador, entonces, de acuerdo a la información que se ha analizado, el salario gira en tomo al valor mínimo de subsistencia fisiológicamente necesario para la vida del obrero (o sea la CBA de la DIGESTYC), esto no contradice el aserto de Marx de que en el capitalismo el salario viene determinado por el valor de la fuerza de trabajo; la prueba de ello debe deducirse del hecho de que si tal situación no se da, como en la economía de El Salvador, el funcionamiento del sistema económico tiene que sufrir perturbaciones sólo por este fenómeno.

La situación observada en los años setenta y ochenta no experimentó cambios en la década de los años noventa. De ese modo, en el siguiente gráfico puede verse que solamente en dos años de esta última década, el salario mínimo de la industria comercio y servicios cubrieron el costo de la canasta nutricional: 


\section{Cuadro 3}

Cobertura de los salarios medios (manufactura)

y mínimos de la canasta básica alimenticia

familiar urbana (CBAU) y rural (CBAR)

\begin{tabular}{rrrrrr}
\hline Años & SM/CBAU & SICS/CBAU & TGA/CBAR & SCAF/CBAR & SAZU/CBAR \\
\hline 1979 & $108.8 \%$ & $94.7 \%$ & $76.7 \%$ & $210.2 \%$ & $132.7 \%$ \\
1980 & $152.5 \%$ & $113.8 \%$ & $68.5 \%$ & $187.7 \%$ & $151.5 \%$ \\
1981 & $154.1 \%$ & $104.9 \%$ & $66.7 \%$ & $182.7 \%$ & $147.4 \%$ \\
1982 & $146.1 \%$ & $97.5 \%$ & $61.5 \%$ & $168.4 \%$ & $135.9 \%$ \\
1983 & $142.2 \%$ & $87.4 \%$ & $54.5 \%$ & $149.2 \%$ & $120.4 \%$ \\
1984 & $132.1 \%$ & $90.8 \%$ & $46.6 \%$ & $127.8 \%$ & $103.1 \%$ \\
1985 & $128.9 \%$ & $82.4 \%$ & $42.9 \%$ & $117.6 \%$ & $94.9 \%$ \\
1986 & $116.2 \%$ & $84.9 \%$ & $62.2 \%$ & $110.7 \%$ & $89.4 \%$ \\
1987 & $103.7 \%$ & $75.3 \%$ & $54.5 \%$ & $97.0 \%$ & $78.3 \%$ \\
1988 & $95.2 \%$ & $82.9 \%$ & $58.4 \%$ & $94.9 \%$ & $78.8 \%$ \\
1989 & $85.3 \%$ & $74.8 \%$ & $52.6 \%$ & $85.5 \%$ & $71.1 \%$ \\
1990 & $110.1 \%$ & $85.5 \%$ & $55.3 \%$ & $93.8 \%$ & $77.9 \%$ \\
1991 & $91.3 \%$ & $79.4 \%$ & $62.6 \%$ & $93.9 \%$ & $78.0 \%$ \\
1992 & $91.9 \%$ & $90.0 \%$ & $62.0 \%$ & $93.1 \%$ & $77.3 \%$ \\
1993 & $84.5 \%$ & $93.6 \%$ & $65.5 \%$ & $79.8 \%$ & $66.3 \%$ \\
1994 & nd & $99.9 \%$ & $66.8 \%$ & $79.8 \%$ & $67.6 \%$ \\
1995 & nd & $99.0 \%$ & $66.8 \%$ & $79.8 \%$ & $67.6 \%$ \\
\hline
\end{tabular}

Fuente: cuadro 3 y 4 de la tcsis.

Siglas: Salario medio de manufactura (SM). Salario de la industria, comercio y servicio (SICS). Tarifa gencral agropecuaria (TAG). Jornal del café (SCAF). Jornal de la caña de azúcar (SAZU). (Cuadro 7 de la tesis).

\section{Gráfico 2}

Nivel de cobertura de la canasta básica que tiene los salarios mínimos

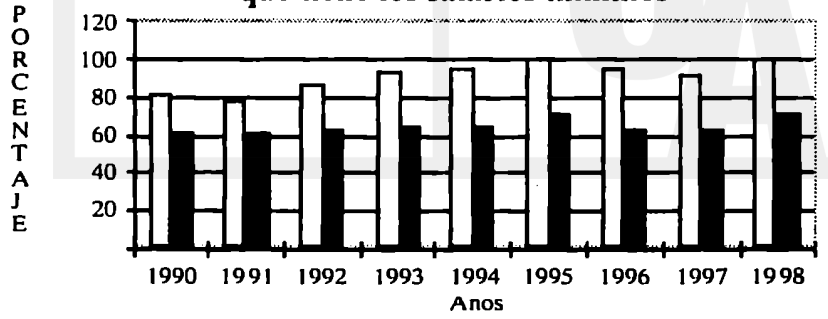

口Salarios de Industria, comercio y servicios

Tarifa Agropec uaria General

Fuente: datos de FUNDE 
$\mathrm{Al}$ analizar la mediana salarial real se puede constatar, sin lugar a dudas, que más de la mitad de nuestra fuerza laboral se encontró en la década recién pasada obteniendo salarios inferiores no sólo al mínimo legal sino también a la magnitud de la canasta nutricional, lo cual se comprueba en el gráfico 3:

\section{Gráfico 3}

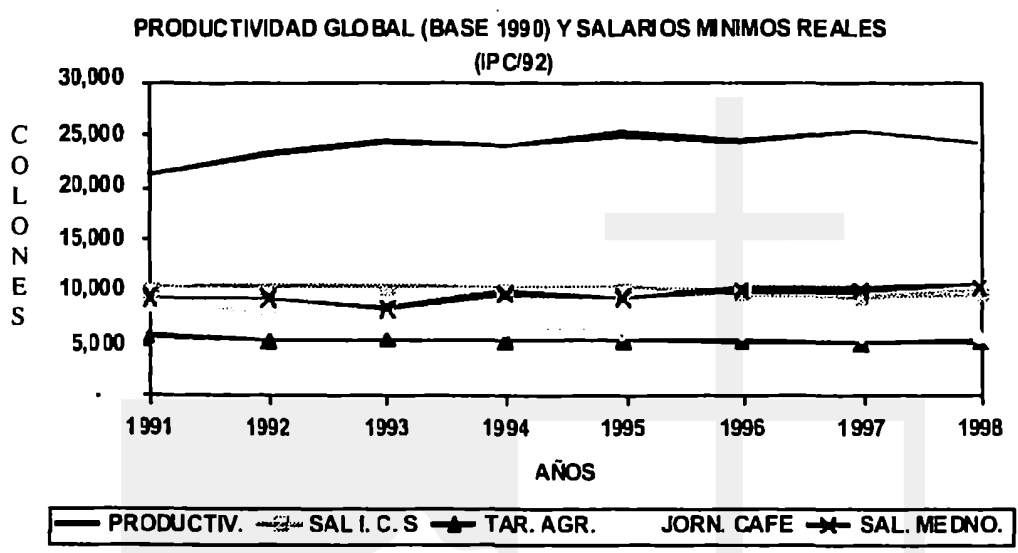

Fuente: EHPM varios números y PNUD, 1997.

Lo cierto es que una vez que se observa en los datos que el salario cubre solamente el mínimo de subsistencia fisiológico; las fluctuaciones propias del mercado lo harán caer en años malos por debajo de ese límite fisiológico; ello hará caer la "calidad normal" del trabajo aún más de lo que se venía deprimiendo debido a que el salario se halla por debajo del valor de la fuerza de trabajo del obrero.

\subsection{Crecimientos de la productividad y de los salarios.}

En el cuadro que se presenta a continuación se muestran las tasas promedios de crecimiento de los salarios reales y de la productividad media tanto de la economía global y de la industria manufacturera, como de la agricultura y el subsector del café:

En el largo período estudiado 1978-1995 los salarios han estado cayendo bastante más rápido que lo que disminuye la productividad. En el caso de la manufactura la productividad se ha mantenido más bien creciendo, no así los salarios medios que a lo largo de los años estudiados han decrecido a un ritmo del $8.4 \%$. En cuanto al subsector del café también puede evidenciarse que la productividad cae con menos rapidez que el salario real. 


\section{Cuadro 4}

Tasas de crecimiento de los salarios reales mínimos y medios (manufactura y sector del café) y de la productividad (precios de 1962)

\begin{tabular}{lccccccc}
\hline Categ./period. & $1970 / 71-$ & $1979 / 80-$ & $1970 / 71-$ & $1978-1980$ & $1980-1989$ & $1989-$ & $1978-$ \\
& $1979 / 80$ & $1989 / 90$ & $1989 / 90$ & & & $1995 *$ & $1995^{*}$ \\
\hline Global & & & & & & & \\
\hline \multicolumn{1}{c}{ Sal. In. Co. Se. } & $\mathrm{Nd}$ & $\mathrm{Nd}$ & $\mathrm{Nd}$ & $12.9 \%$ & $-8.8 \%$ & $-1.4 \%$ & $-3.8 \%$ \\
Sal. Agrop. & $\mathrm{Nd}$ & $\mathrm{Nd}$ & $\mathrm{Nd}$ & $-2.7 \%$ & $-7.1 \%$ & $-2.6 \%$ & $-5.0 \%$ \\
Productividad & $\mathrm{Nd}$ & $\mathrm{Nd}$ & $\mathrm{Nd}$ & $-4.0 \%$ & $-2.4 \%$ & $1.6 \%$ & $-1.2 \%$ \\
\hline Manufactura & & & & & & & \\
\hline \multicolumn{1}{c}{ Salarios/med. } & $\mathrm{Nd}$ & $\mathrm{Nd}$ & $\mathrm{Nd}$ & $10.3 \%$ & $-12.2 \%$ & $-8.1 \%$ & $-8.4 \%$ \\
Productividad & $\mathrm{Nd}$ & $\mathrm{Nd}$ & $\mathrm{Nd}$ & $-5.0 \%$ & $0.9 \%$ & $-0.3 \%$ & $0.3 \%$ \\
\hline Agropecuario & & & & & & & \\
\hline Salarios/t. G. A. & $\mathrm{Nd}$ & $\mathrm{Nd}$ & $\mathrm{Nd}$ & $-2.0 \%$ & $-9.2 \%$ & $-3.8 \%$ & $-6.9 \%$ \\
Productividad & $\mathrm{Nd}$ & $\mathrm{Nd}$ & $\mathrm{Nd}$ & $9.2 \%$ & $-3.8 \%$ & $3.4 \%$ & $-0.3 \%$ \\
Subsect./cafe & & & & & & & \\
Salarios/cafe & $4.7 \%$ & $-16.2 \%$ & $-6.0 \%$ & $\mathrm{Nd}$ & $\mathrm{Nd}$ & $\mathrm{Nd}$ & $\mathrm{Nd}$ \\
Productividad & $-1.2 \%$ & $-2.2 \%$ & $-1.6 \%$ & $\mathrm{Nd}$ & $\mathrm{Nd}$ & $\mathrm{Nd}$ & $\mathrm{Nd}$ \\
\hline
\end{tabular}

Fuente: elaboración propia basada en datos del MIPLAN, BCR y de Aguilar, et al.; 1992.

Siglas: Tarifa general agropecuaria (TGA). Salarios industria, comercio y servicios (SAL. IN. CO. SE.). Salario agropecuario (SAL. AGROP.) *Para la manufactura y el sector agropecuario estas tasas se han calculado hasta 1993.

Los datos que se muestran en el cuadro indican que en el lapso estudiado se han sucedido etapas, las cuales comparadas unas con otras en cuanto a los ritmos de crecimiento de los salarios reales y la productividad no permiten intuir una relación de determinación de los salarios reales sobre la productividad. No obstante, para poder hacer una mejor aproximación es conveniente hacer un estudio más preciso, utilizando modelos de regresión.

\subsection{La vinculación salarios-productividad: modelo de regresión de la eco- nomía global.}

Para estudiar lo que ocurre a nivel de toda la economía se utilizarán dos modelos: uno, en donde la regresión se corre relacionando la productividad con el salario nominal de la industria, el comercio y los servicios, el índice de precios implícito, la formación bruta del capital fijo global por trabajador, la tasa de empleo y la variable cualitativa de la guerra. El segundo modelo econométrico relaciona productividad, los salarios-producto dé la industria, el comercio y servicios de varios períodos, la relación capital-producto y la tasa de empleo (que incorpora los efectos de la guerra). En este caso no se presenta el cálculo con el 
salario a precios constantes deflactados con el IPC debido a que los resultados no contradicen a los obtenidos con el salario-producto.

Este modelo comprende el período 1978-1995, o sea, $\mathrm{N}=18$. Los símbolos del primer modelo son:

PRG: producto por trabajador de toda la economía, PIB a costo de factores (sin incluir gobiemo) por trabajador ocupado, colones de 1962.

SICN: salario de la industria, comercio y servicios, el indicador es el salario mínimo promedio mensual anualizado en colones (multiplicado por 12).

IPI: deflactor implícito del PIB, base 1962; índice.

FBCG: formación bruta de capital fijo de la economía (sector privado) por trabajador (colones de 1962).

EMG: tasa de empleo medida como ocupados/PEA total.

D: es una variable cualitativa que asigna 1 a los años en que existían condiciones de paz y 0 a los años en que se dio la guerra civil. Se espera una pendiente positiva para esta variable.

Los resultados de la regresión se presentan como sigue:

\section{Regresión 1: Economía global}

$\mathrm{PRG}=4197.15+0.09 \mathrm{SICN}-66.62 \mathrm{IPI}+3.00 \mathrm{FCG}-2726.89 \mathrm{EMG}+139.74 \mathrm{D}-1.07 \mathrm{AR}(-4)$

D. E.

(45.16) $\quad(0.03$

$\mathrm{t}$ (Est.) (77.67) (2.93)

$\mathrm{gl}=12$ significación $=5 \% \quad \mathrm{t}($ Tabla $)=2.18 \quad \mathrm{DW}=1.38, \mathrm{dl}=0.71 ; \mathrm{du}=2.06$ $\begin{aligned} \mathrm{R}^{2}=93.09 \% \quad \mathrm{~N}=18 \quad \mathrm{AR}(-4)= & \begin{array}{l}\text { regresivo con cuatro rezagos (de cuar- } \\ \text { to orden) para corregir autocorrelación. }\end{array}\end{aligned}$

En este modelo todos los parámetros son significativos. El Durbin-Watson indica que la prueba no es concluyente pues se ubica en la zona de indecisión, al $5 \%$; sin embargo al analizar el comportamiento de los residuos no se detectan tendencias de autocorrelación positiva, mientras que la prueba indica que no existe autocorrelación negativa, al igual que lo indican los datos. La explicación de las variables dependientes sobre la productividad alcanza el 93.09\%. Los signos de SICN y el del IPI, se encuentran de acuerdo con la teoría. Lo mismo sucede con las otras variables (FCG, EMG y D). La guerra tuvo un efecto 
importante indicando que la productividad disminuyó en los períodos del conflicto.

En la economía global también se crnprueba que los gastos de trabajo, representados por el indicador EMG, aumentan por las perturbaciones que causa a la producción el deterioro de la capacidad productiva de la fuerza de trabajo, lo cual es la consecuencia de que se tenga que usar, por ejemplo, más fuerza de trabajo para paliar las ausencias de los trabajadores con salud deteriorada, mientras que por otra parte la intensidad se reduce debido a los mismos problemas de la salud de los obreros.

Los símbolos que se definen a continuación corresponden al segundo modelo:

SIC: salario-producto de la industria, comercio y servicios nominal, el indicador es SICN/IPI. EMGSICI: estimado de la tasa de empleo medida como ocupados/PEA total. SIC $_{.1}$ : salario-producto con "i" períodos de rezagos. donde $\mathrm{i}=1,2,3, \ldots, \mathrm{n}$

Las otras variables ya han sido definidas. El resultado del cálculo se escribe:

\section{Regresión 2: Economía global}

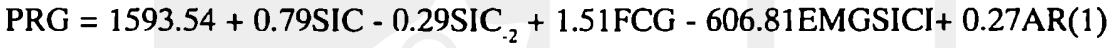

D. E. (246.91)

$\mathrm{t}$ (Est.) (6.45)

$\mathrm{gl}=14$ significación $=5 \% \quad \mathrm{t}($ Tabla $)=2.15 \quad \mathrm{DW}=1.85 \quad \mathrm{R}^{2}=95.7 \% \quad \mathrm{~N}=18$

Todas las pendientes de la regresión son significativas al 5\%. El estadístico Durbin-Watson queda en el área de indeterminación al $5 \%$ pero indica que no existe autocorrelación positiva al 1\%; Sin embargo, el análisis del comportamiento de los residuos sugieren que no existe autocorrelación entre los errores, en cuanto a la autocorrelación negativa el DW señala que ésta no existe. El grado de explicación es del $95.7 \%$.

En la regresión se ha incluido una variable estimada, es el coeficiente de empleo EMGSICl, esta estimación se realizó debido a que tanto la variable de la guerra como uno de los salarios rezagados $\left(\mathrm{SCl}_{-1}\right)$ mostraban una alta correlación con la tasa de empleo; por otro lado esta última se mostraba independiente de la productividad al correr una regresión uniecuacional. La variable cualitativa de la guerra y el salario con un rezago hacen un buen ajuste de la tasa de desempleo, de manera que al incluirse la variable de la ocupación estimada se calcula de modo indirecto los efectos de la guerra y del salario rezagado sobre la 
productividad. Pero también la variable estimada indica el influjo de los gastos de trabajo sobre el producto por trabajador. En la regresión que se ha calculado se puede ver que el impacto del empleo es negativo indicando que la intensidad del trabajo se ha mermado como consecuencia del ya mencionado deterioro de la capacidad productiva.

Algunos autores econometristas mencionan que al usar datos rezagados es conveniente seguir la regla consistente en que si una variable con rezago al momento del cálculo de sus parámetros, estos comienzan a mostrar un comportamiento alternativo en relación a su signo deben interrumpirse los rezagos, por otra parte si choca con la teoría debe suprimirse esa variable que arroja el parámetro incoherente con los preceptos teóricos.

En las regresiones calculadas en esta investigación se presentó el problema de los signos alternativos, no obstante ello no chocaba con la teoría pues existen planteamientos teóricos que asocian las caídas de la productividad a los aumentos de salario y viceversa. Sin embargo, al calcularse el efecto total, esto es, dándoles valor unitario a las variables rezagadas del salario real, el resultado que se obtiene en la economía global es de 0.50 ó $50 \%$ lo que significa que en el estado de nuestra economía la relación positiva que el salario tiene con respecto a la productividad es superior que los efectos negativos que sobre la misma tiene el salario. De igual forma, al agregar los efectos que los cambios salariales unitarios generan en la productividad agropecuaria y no agropecuaria, el resultado es coherente con el obtenido en la economía global ( 0.25 ó $25 \%)$.

El estudio econométrico de la economía global reafirma lo que se ha podido constatar en todos los sectores:

El salario real determina a la productividad. Cuando esta última aumenta y el salario real se deprime por largos períodos el efecto que tal situación genera, haciendo caer la capacidad productiva del trabajador (por el deterioro de salud, educación, nutrición, etc.), termina por provocar un descenso en la productividad y, también, hace que los gastos de trabajo se aumenten al mismo tiempo que la intensidad del trabajo cae, esto último debido a las mismas razones que determinan que la productividad se desplome.

Ahora, conviene tratar un tema que es importante para la evidencia que se ha observado en este apartado y se refiere a los datos sobre la situación de salud de los trabajadores.

\subsection{Los indicadores de salud de los trabajadores}

Tanto en el análisis empírico como en el teórico se ha hecho referencia al fenómeno de que al mismo tiempo que los salarios caen la salud (así como otros aspectos importantes) de los obreros se deteriora. Pero la salud es un factor fundamental para el buen desenvolvimiento de la capacidad productiva del tra- 
bajador y también para mantener una intensidad media del trabajo en condiciones constantes o en aumento.

Se ha comprobado que dada la situación decreciente de los salarios reales en el período estudiado, la economía de El Salvador se encuentra en una situación en la cual la productividad está disminuyendo especialmente por las reducciones de los salarios reales, lo que también está impactando de forma negativa a la intensidad pues los gastos de trabajo aumentan mientras que la intensidad junto a la productividad decrecen. Obviamente que bajo estas condiciones de constante reducción de la intensidad, la propia intensidad media del trabajo puede decrecer, lo cual se traduce por sí mismo en una disminución de la productividad, esto es, ningún trabajador podrá alcanzar la intensidad media más alta que se venía teniendo antes, es como si hubiesen cambiado las condiciones naturales, lo cual como ya se sabe es un factor determinante en la productividad ${ }^{15}$.

Existe evidencia convincente acerca del deterioro de la salud de los trabajadores, tanto en la economía global como en sectores como la maquila. Analicemos, en primer lugar, la economía global, para luego considerar el caso de las maquilas. En el gráfico siguiente se muestran las consultas médicas generales en el Instituto Salvadoreño del Seguro Social (ISSS) a los trabajadores por riesgos comunes y profesionales a lo largo de 13 años, en los cuales el salario real se mantuvo decreciendo:

\section{Gráfico 4}

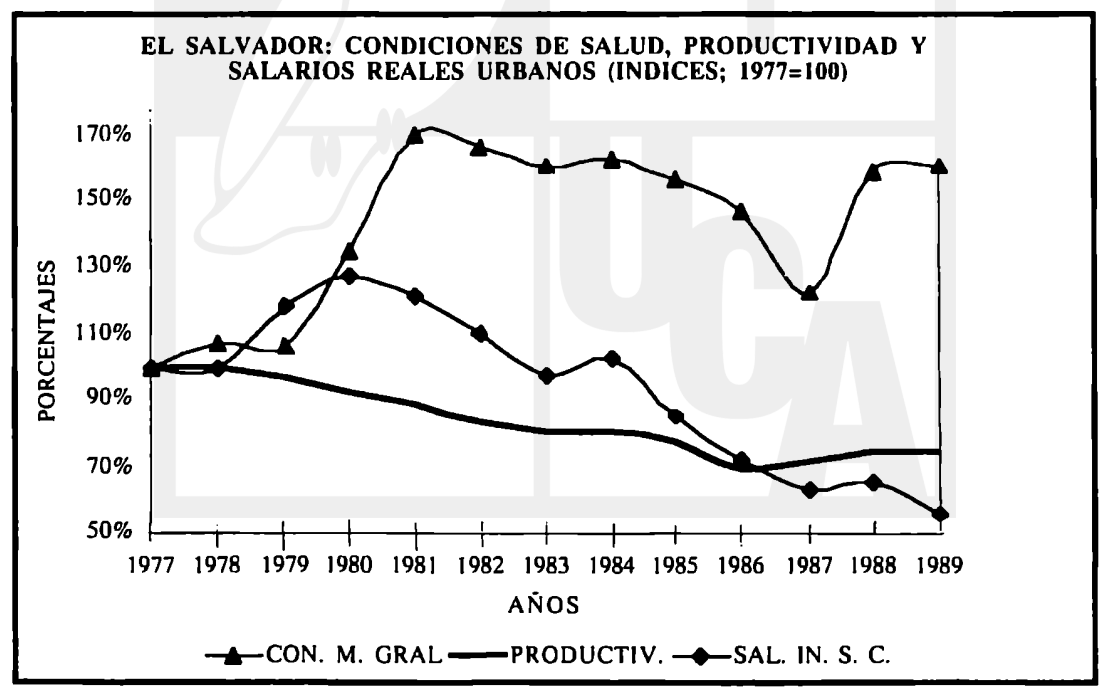

Fuente: elaboración propia. Ibid. SIMBOLOS: CON. M. GRAL.; consulta de medicina general; SAL. IN. S. C.; salarios de la industria, servicios y comercio. 
En el gráfico 4, en donde se presentan las atenciones de emergencias del ISSS a los trabajadores, es notoria la forma en que las condiciones de salud se fueron deteriorando con la caída de los salarios reales, al mismo tiempo que la productividad global mostraba problemas en su dinámica.

\section{Gráfico 5}

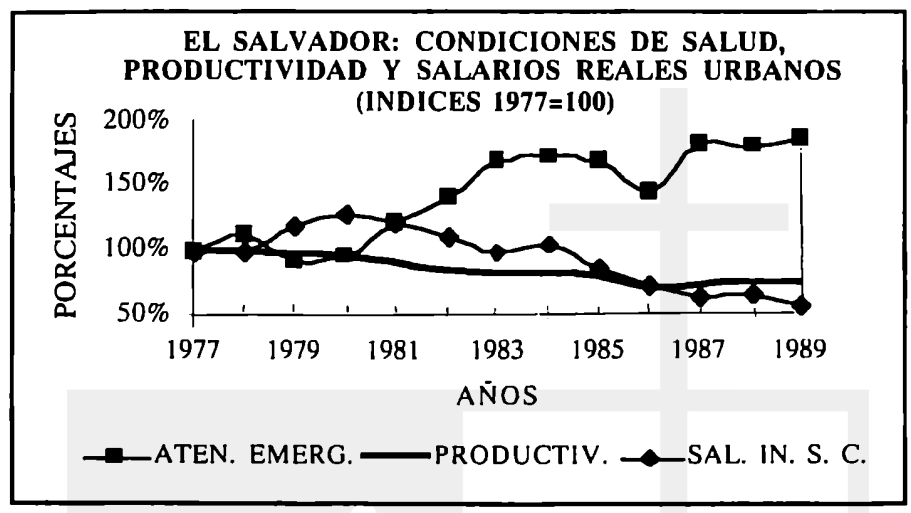

Fuente: elaboración propia. Ibid. SIMBOLOS: ATEN. EMERG.; atenciones de emergencia. SAL. IN. S. C.: salarios de la industria, servicios y comercio.

De acuerdo con esos dos gráficos no cabe la menor duda de que la caída de los salarios se encuentra asociada al deterioro de las condiciones de salud de los trabajadores, lo cual es de fundamental importancia para entender tanto los planteamientos teóricos como los resultados empíricos.

\subsection{Salarios reales, productividad y tipos de beneficios: el problema de la distribución.}

La productividad solamente puede importar a los empresarios en cuanto a la vinculación que tiene con su rentabilidad, con sus tipos de beneficios. Una vez que se establece el hecho del deterioro de la capacidad productiva del trabajador y que tal fenómeno tiene una influencia considerable sobre la productividad, es posible encontrar indicios de que la caída de esta última debido a la disminución de la eficiencia personal del trabajador como consecuencia de sus bajos salarios reales, influye en los tipos de beneficios provocando su disminución. El efecto puede ser tan grave que incluso la participación de los empresarios en el producto, en términos absolutos, pueden verse reducidos. 
Esta relación se ha podido evidenciar en subsectores de la producción agrícola como el café y el algodón en el período comprendido entre el ciclo 1970/71 y 1979/80, especialmente cuando se analiza el coeficiente excedente bruto-salario real. En ese período los salarios presentaron una tendencia decreciente, mientras la productividad mostró signos de estancamiento en el café y una leve tendencia decreciente en el algodón ${ }^{16}$.

Para investigar si este fenómeno se da en los otros sectores económicos, se ha tomado el caso de la manufactura. En el cuadro que sigue se muestran, la relación capital-trabajo, la fracción de la productividad que le corresponde a los capitalistas, la tasa de beneficio (indicador de la tasa de ganancia), la productividad y el salario por hora.

\section{Cuadro 5}

Relación capital-trabajo, distribución, Productividad y tasa de ganancia (en colones)

\begin{tabular}{llllll}
\hline Años & A/B & r(A/B $)$ & $r(\%)$ & $\begin{array}{l}\text { product. } \\
(\mathrm{H} / \mathrm{H})\end{array}$ & $\begin{array}{l}\text { Salario } \\
\text { hora }\end{array}$ \\
\hline 1982 & 0.93 & 2.83 & 305.0 & 4.43 & 1.60 \\
1983 & 0.92 & 2.73 & 295.6 & 4.28 & 1.55 \\
1984 & 1.02 & 2.94 & 287.4 & 4.40 & 1.46 \\
1985 & 1.00 & 3.37 & 337.7 & 4.65 & 1.29 \\
1986 & 1.81 & 4.06 & 224.9 & 5.04 & 0.98 \\
1987 & 1.36 & 4.33 & 319.6 & 5.12 & 0.78 \\
1988 & 1.31 & 4.62 & 353.0 & 5.28 & 0.66 \\
1989 & 1.23 & 4.97 & 404.7 & 5.53 & 0.56 \\
1990 & 1.24 & 4.52 & 365.3 & 5.10 & 0.59 \\
1991 & 1.49 & 4.45 & 298.5 & 4.96 & 0.50 \\
1992 & 1.83 & 4.84 & 264.6 & 5.30 & 0.46 \\
1993 & 1.97 & 5.06 & 257.1 & 5.46 & 0.40 \\
\hline
\end{tabular}

Fuente: MIPLAN, 1992.

Simbologia: A/B; relación capital-trabajo (formación bruta de capital en la manufactura/ ocupados en el sector). $\mathrm{r}(\mathrm{A} / \mathrm{B})$; parte de la productividad que le corresponde a los empresarios. r; tasa o tipo de beneficio (ganancia). Productividad por hora-hombre $(\mathrm{H} / \mathrm{H})=$ salario por hora $+\mathrm{r}(\mathrm{A} / \mathrm{B})$.

En el cuadro 5 puede observarse, la manera en que la constante caída de los salarios por hora hace que la productividad (por hora-hombre) comience a disminuir, esta depresión de la productividad provoca la reducción del tipo de beneficio ( $\mathrm{r}$ ), el cual es muy sensible a las caídas de la productividad debido a la tendencia al aumento experimentado por el coeficiente capital-trabajo (A/B; el 
que para el caso salvadoreño es lícito considerarlo asociado a los incrementos de la composición en valor del capital). Con sólo que el crecimiento de la productividad sea débil, la tasa de beneficio tiende a reducirse. Esa situación también puede evidenciarse en el gráfico 6.

\section{Gráfico 6}

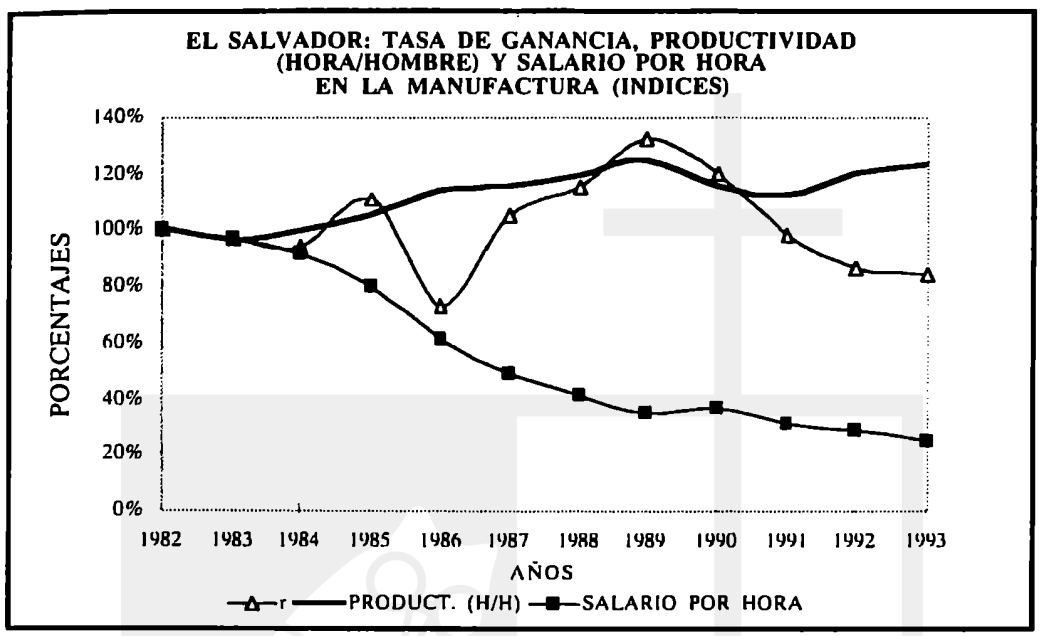

Fuente: MIPLAN, 1992. Cuadro 18 de la tesis.

Es necesario hacer notar que la participación de los capitalistas [ $\mathrm{r}(\mathrm{A} / \mathrm{B})]$, sin embargo, no se ve afectada de manera directa y rápida por los efectos de la reducción de los salarios reales sobre la productividad ni de la tasa de beneficio; pero cuando los decrecimientos de la productividad son considerables y sostenidos (como en 1990 y 1991) aun la participación de los empresarios en el producto por trabajador puede verse reducida.

Para 1990, los resultados obtenidos por el BCR en el análisis de la matriz insumo-producto (ver cuadro 5) permiten comprobar que la participación de los trabajadores entre los 12 años que median entre 1978 y 1990 se ha visto reducida permitiendo, por otra parte, que el excedente de explotación se vea aumentado. En otras palabras estos datos corroboran el efecto de que los ritmos de crecimiento de la productividad en el largo plazo hayan sido superiores a las tasas de crecimiento del salario real ${ }^{* *}$. 
Cuadro 6

\begin{tabular}{|c|c|c|}
\hline \multicolumn{3}{|c|}{ Distribución factorial del ingreso nacional $1978-1990$} \\
\hline Categorias/años & 1978 & 1990 \\
\hline Remuneraciones a empleados & $36.12 \%$ & $32.53 \%$ \\
\hline Consumo de capital fijo & $4.65 \%$ & $4.72 \%$ \\
\hline Impuestos indirectos netos de subsidios & $6.18 \%$ & $6.37 \%$ \\
\hline Excedente de explotacion & $53.05 \%$ & $56.38 \%$ \\
\hline Valor bruto de la produccion & $100.00 \%$ & $100.00 \%$ \\
\hline
\end{tabular}

Fuente: Ibisate, F. J. 1986 y 1994.

Cuadro 11 de la tesis.

No obstante, los empresarios capitalistas deben tener presente que a pesar de que su participación en el producto experimenta aumentos como resultado de la depresión de los salarios, en condiciones de aumento de la productividad; tal situación puede revertirse si al ocurrir el deterioro de la capacidad productiva del trabajador, el producto por obrero sufre decrecimientos fuertes y sostenidos tal y como ha sido el caso de la manufactura.

\subsection{Salarios reales, fuerza de trabajo y cambio técnico.}

Considerando que existe teóricamente una interrelación entre los aumentos tecnológicos, el crecimiento del nivel técnico-cultural de la mano de obra y los aumentos de la productividad; convendría encontrar un indicador que nos permitiese descubrir si tal relación ocurre en la práctica.

Uno de estos indicadores es el coeficiente capital-trabajo; en teoría si este coeficiente aumenta en la rama i la productividad en la misma también lo hace, y si todas las demás condiciones se mantienen constantes*, debe ocurrir que la relación capital-trabajo global aumente y, por lo tanto, la productividad de toda la economía.

Debido a los inconvenientes que presenta la medición del stock de capital se hará uso para medir el coeficiente capital-trabajo del indicador formación bruta del capital fijo. También se utilizará como indicador del coeficiente capital trabajo, el consumo de energía eléctrica por trabajador para de este modo poder hacer una observación precisa de las vinculaciones de los cambios tecnológicos y la productividad.

En el gráfico se presentan los dos indicadores del coeficiente capital-trabajo junto con la productividad de la economía global. En general, a lo largo de todo el período analizado se puede decir que, en lo que se refiere a la economía 
global, el coeficiente tecnológico capital trabajo (medido a través de los dos indicadores que se han mencionado) no parece ejercer la influencia que la teoría predice, esto es, que al crecer la relación capital-trabajo la productividad también debería hacerlo, si no con la misma proporcionalidad, por lo menos con una proporcionalidad bastante cercana.

\section{Gráfico 7}

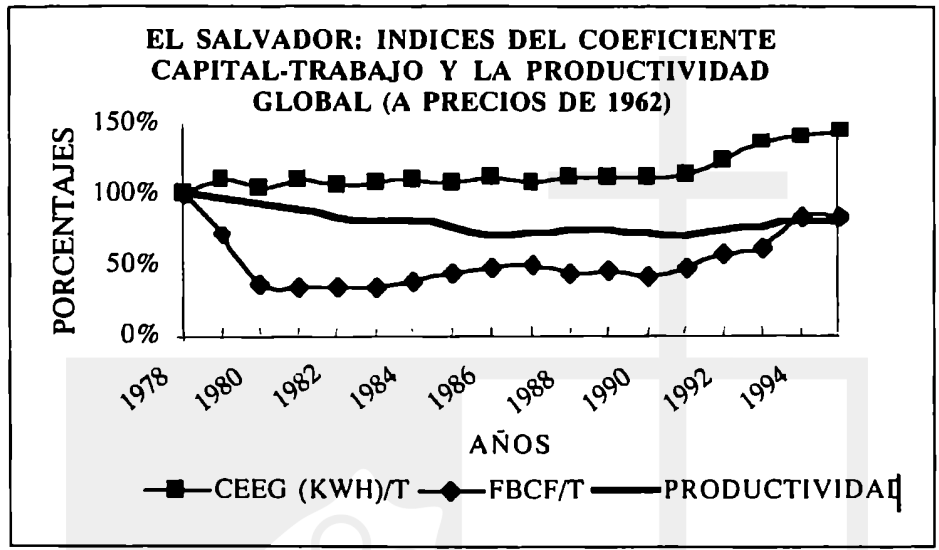

¿Qué es lo que hace que la productividad no reaccione con la correspondiente proporcionalidad a los cambios tecnológicos operados en la economía? Dos respuestas relevantes podrían darse a esta cuestión:

a. La primera hace mención al problema de los agregados, y consiste en sostener que la productividad agregada o global se desploma debido a que no hay sectores que hacen considerables cambios tecnológicos $y$, por lo tanto, sus dinámicas productivas son bajas y provocan el pobre desenvolvimiento de la productividad global.

b. Por cuanto en la definición de la productividad entran los salarios, se puede afirmar, para responder a la pregunta, que el deterioro de la productividad se debe a la secular disminución de los salarios y a sus ínfimos niveles.

Debe comprenderse que cada una de las respuestas no excluye a la otra; sin embargo, si se vuelve a los gráficos se puede notar que ya en la economía global se capta la rigidez de la productividad ante los cambios de los indicadores del coeficiente capital trabajo (atender las brechas entre estos indicadores y el índice de productividad, gráfico 7), y cuando se observa lo que ocurre en la esfera productiva no agropecuaria es posible percatarse de que su comportamiento productivo y tecnológico contribuye con lo que sucede en la economía global, de la 
misma manera la manufactura también contribuye con esa rigidez de la producción por trabajador en la esfera no agropecuaria al mostrar una débil correspondencia de su productividad a los cambios tecnológicos.

Todo parece indicar que es el salario (o el problema de la distribución si se quiere) el causante de lo que en apariencia se presenta como una rigidez en el crecimiento de la productividad con respecto a los ritmos de aumento del coeficiente capital-trabajo.

\subsection{Salarios, productividad y aprovechamiento de la tecnología en la maquila.}

Con los datos de las series de tiempo fue posible detectar en la economía global y en la maquila la relación positiva entre los salarios y la productividad, especialmente entre 1981-1989. Esta asociación del producto por trabajador con el salario se explica por dos efectos: uno, el impacto de los salarios actuales o presentes debido al papel determinante que estos tienen sobre la capacidad psicológica y moral del trabajador $\mathrm{y}$, dos, al efecto rezagado de los cambios salariales sobre las condiciones psicofisiológicas del obrero. Pero la influencia del salario sobre la productividad no es tan simple, hay años por ejemplo (19791981 ) en donde encontramos relaciones inversas o negativas, esto se debe a que los salarios son contenidos por los empresarios para elevar los niveles y tasas de ganancia y plusvalía mientras el producto por trabajador aumenta.

Pero se sabe que la productividad depende también, de modo fundamental, de la tecnología, es necesario por lo tanto, conocer qué papel está jugando la tecnología en el comportamiento de la productividad para este caso de la maquila. Los datos analizados en la Zona Franca de San Bartolo indican que la composición en valor se ve influida en dirección positiva por la composición técnica, la típica modalidad capitalista de elevar el progreso técnico. En lo referente a la productividad, ésta no sigue con mucha fidelidad a la composición orgánica (especialmente cuando se observa en valor), desaprovechando la capacidad tecnológica en algunos años por las perturbaciones de las caídas salariales.

Esta evidencia, sin embargo, no es del todo concluyente pues se necesita saber si realmente ocurre toda la cadena de interacciones que arranca, por ejemplo, de la caída de los salarios para seguidamente deteriorar la salud de los trabajadores; sucederle luego el decrecimiento de la productividad y, finalmente, de la plusvalía.

En lo que respecta a las series de tiempo no se poseen datos que faciliten detectar la mencionada cadena de relaciones de causa y efecto; no obstante, existen datos de corte transversal que hacen posible comprobar dicha secuencia de interacciones en el sector de la maquila. El cuadro que se expone a continuación presenta esos datos: 


\section{Cuadro 7}

El Salvador: Relación entre los salarios ( $\phi)$, la salud, El coeficiente capital-trabajo* y la productividad $(\varnothing)$

(Datos mensuales)

\begin{tabular}{lrlcccc}
\hline Empresas & $(\mathrm{K} / \mathrm{L})^{*}$ & Productiv. & Sal. Unit & Su/Prod. & $\begin{array}{c}\text { Det. } \\
\text { Salud }(\%)\end{array}$ & $\begin{array}{c}\text { T. Plusvalía } \\
(\%)\end{array}$ \\
\hline CORPAK & 369 & 2,784 & 989 & 36 & 0 & 1.82 \\
PRIMO & 250 & 2,671 & 918 & 34 & 38 & 1.91 \\
AVX & 1,179 & 3,426 & 979 & 29 & 56 & 2.50 \\
\hline
\end{tabular}

Fuente: elaboración propia en base a Arriola, J.; 1993: 59, 68, 86, 150.

Simbologia: $(\mathrm{K} / \mathrm{L}),\left({ }^{*}\right)$ relación capital-trabajo medida como el cociente entre la cantidad de Kilovatios/hora (KWH) consumidos por trabajador. SAL. UNIT., salarios unitarios. SU/PROD., cociente: salarios unitarios entre productividad. DET. SALUD, detcrioro de salud. T. PLUSVALIA, tasa de plusvalía.

Para un mejor entendimiento de lo que refleja el cuadro, es pertinente hacer referencia a las empresas que ahí aparecen. AVX es un negocio de componentes electrónicos; PRIMO es una empresa de ropa femenina y CORPAK es un negocio de bolsas decorativas.

La empresa AVX absorbe el $23 \%$ del empleo en la Zona Franca de San Bartolo, PRIMO el $14 \%$ y CORPAK el $3 \%$, en otras palabras, las tres empresas juntas representan el $40 \%$ del empleo de esa Zona Franca.

Lo que en el cuadro se denomina "deterioro de salud" es el resultado obtenido de un test que fue cursado entre los trabajadores de la maquila el cual se denomina "Test de Salud Total" (TST) 17 que busca captar las situaciones de desgaste psíquico-físico en el trabajo. Este test se basa en un cuestionario que asigna una puntuación de uno a respuestas como "malo" o "con frecuencia" y cero a las otras. Posteriormente se establecen los porcentajes de los cuestionarios que tienen puntajes igual o mayor que 9, a partir del cual se considera "señal de alarma" y "zona de riesgo de sufrimiento psíquico". La puntuación mínima es de cero y la máxima de 22 (Arriola, J.; 1993: 85).

En el cuadro 7 se han resumido bajo la columna "deterioro de salud" los porcentajes de trabajadores que se encuentran en situación de riesgo de daño psíquico-fisico.

Los datos de la empresa CORPAK que se ilustran en el cuadro indican que dado que el "deterioro de salud" en esa empresa es de $0 \%$, entonces se puede suponer que en ese momento dicha empresa estaba pagando aproximadamente la fuerza de trabajo. Pero debido a que las tres empresas del análisis son 
cualitativamente distintas, no es posible comparar sólo en términos absolutos los salarios de las mismas de tal manera que se vuelve necesario también establecer un indicador relativo, y se ha optado por tomar el coeficiente que resulta de dividir los salarios unitarios entre la productividad para poder realizar las comparaciones. Debe quedar claro que tal procedimiento es justificado debido a la necesidad de hacer una evaluación de corte transversal entre empresas y trabajadores cualitativamente distintos, diferencias como las que podrían existir entre PRIMO, empresa de ropa femenina, y AVX, industria de componentes electrónicos.

En base a la explicación anterior, la estructura salarial (salarios/productividad) que más o menos cubriría el valor de la fuerza de trabajo es la de la empresa CORPAK. De esta manera observando el cuadro 7 se puede constatar que a medida que los salarios decaen, en términos de la estructura salarial, las condiciones de salud de los trabajadores se deterioran y con ello la productividad disminuye o no puede alcanzar su nivel potencial, esto último es lo que sucede con la industria AVX.

Esa situación también se puede ver considerando el comportamiento de los salarios en términos absolutos. Tanto la productividad y los salarios son más bajos en la empresa PRIMO que los evidenciados en CORPAK; AVX tiene mejores salarios absolutos, tecnología y, por lo tanto, productividad que PRIMO pero la estructura salarial de esta última empresa es superior a la de la empresa de componentes electrónicos (AVX) razón por la cual vemos un mayor deterioro de la salud de sus trabajadores, lo que no le permite una plena utilización de la tecnología y por ende alcanzar su nivel más alto de la productividad (el potencial), ello se comprueba al comparar el producto por trabajador de CORPAK y AVX; la primera tiene menos tecnología pero un salario absoluto y estructura salarial más elevada que la segunda, lo que provoca que su productividad se acerque a su nivel potencial y se encuentre próxima a la de AVX.

De este modo, el cuadro también refleja cómo el deterioro de la capacidad productiva del trabajador no permite el completo aprovechamiento de la tecnología empleada, por ejemplo, mientras AVX supera a PRIMO y a CORPAK en un $372 \%$ y $220 \%$, respectivamente, en lo referente a la relación capital-trabajo, solamente las sobrepasa en un 28.3 y $23.1 \%$, respectivamente, en lo relativo a la productividad. La tasa de plusvalía, sin embargo, no presenta indicios de reducirse; pero no parece que exista una diferencia correspondiente a las tecnologías utilizadas por cada empresa, de acuerdo con el indicador capital trabajo.

Así las cosas, los datos de la maquila correspondientes a la Zona Franca de San Bartolo permiten evidenciar las hipótesis que se sostienen en este artículo ${ }^{18}$.

\subsection{Comportamiento de la producción y el PIB PER CAPITA actual.}

Queda por saber si en los últimos años se ha reflejado en el producto la tendencia a la desaceleración, habría que esperar que tal cosa ocurriese dada la 
evidencia que se ha presentado en lo relativo a la productividad; para ello se puede utilizar un indicador del crecimiento de la economía, esto es, el Producto Interno Bruto por habitante y su tasa de variación. En el gráfico que sigue se muestra el comportamiento de este indicador a lo largo de la década:

\section{Gráfico 8}

\section{PIB POR HABITANTE Y TASA DE VARIACION}

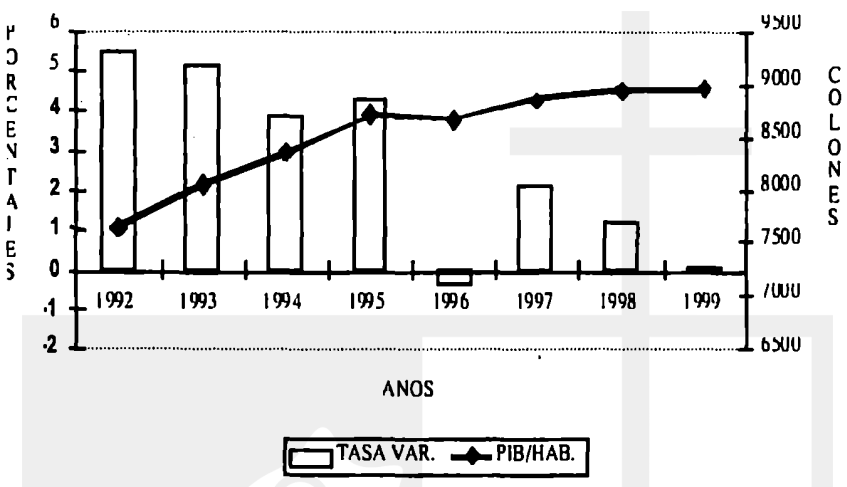

Fuente: Análisis de Coyuntura, Estudios Centroamericanos (ECA), UCA, Febrero-marzo, 2000.

EI PIB por habitante comprueba de nuevo que la economía está experimentando un debilitamiento en su crecimiento económico19, y que, de acuerdo con lo que se ha dicho, esta debilidad responde en buena medida al deterioro de la capacidad productiva del trabajador debido a que no logra llenar sus necesidades básicas, esto es, nutricionales, educativas, de salud, etc.

\section{Conclusiones}

$>$ El comportamiento económico de El Salvador a lo largo de aproximadamente 25 años evidencia una relación de determinación positiva (aunque no es la única) de los salarios reales sobre la productividad lo cual permite verificar que con las caídas de los salarios reales la productividad tiende primero a estancarse y luego a disminuir.

$>$ De este modo la tecnología, factor muy importante del crecimiento de la productividad, no es totalmente aprovechada, impactando de modo fundamental en el crecimiento y, en general, el desarrollo económico salvadoreño. 
- Los 25 años que se han analizado se caracterizan por presentar disminuciones persistentes y estancamiento en el salario real de manera que se constata que este último se encuentra por debajo de los indicadores del valor de la fuerza de trabajo (como la canasta básica ampliada y la canasta de mercado); lo que lleva a deducir que la reducción tendencial de la productividad se ha debido a las persistentes disminuciones y estancamiento del salario real $y$, derivado de ello, al deterioro de la capacidad productiva del trabajador.

$>$ La importancia de las condiciones de la fuerza de trabajo para la productividad y el crecimiento económico ha sido reconocido desde hace mucho tiempo por economistas tan importantes como Smith, Ricardo y Marshall.

$>$ Sin embargo, lo anterior parece ser desconocido por los diseñadores de la política económica en El Salvador $y$, antes bien, operan en sentido contrario a las opiniones de los mencionados economistas, de tal modo que en lugar de mejorar las condiciones salariales de los trabajadores más bien se empeoran con el consiguiente impacto negativo en la eficiencia laboral.

$>$ Finalmente, una importante conclusión de la teoría valor de la fuerza de trabajo-productividad, consiste en que es un planteamiento que, al estilo de la teoría de Smith y los neoclásicos, establece la posibilidad de alcanzar el equilibrio económico con ventajas para todos sus agentes siempre que se cumplan ciertas condiciones, enfatizando como una de las más importantes la cobertura, a través del salario, del valor de la fuerza de trabajo.

\section{Recomendaciones}

$>$ La recomendación principal que se deduce de este estudio es que el salario real de los trabajadores tiene que aumentar hasta el punto de alcanzar una canasta de productos que represente el valor de la fuerza de trabajo, que como se dejó establecido se podría aproximar a la canasta de mercado.

$>$ Los salarios reales tienen que aumentar al mismo ritmo de la productividad si se pretende mantener constante la distribución del ingreso en el largo plazo.

$>$ El incremento de los salarios reales tiene que hacerse de modo gradual y como resultado de estudios que señalen aquellos sectores en los cuales los niveles tecnológicos no se reflejan en el comportamiento de la productividad y cuyos salarios son bajos.

$>$ El alza de los salarios reales debe darse a través de los aumentos en los salarios nominales (salarios mínimos), los cuales no deben ir acompañados de incrementos de precios.

$>$ La gradualidad de los aumentos salariales puede ser que no permita una rápida recuperación del producto por trabajador de manera que el Estado y 
los empresarios privados deben aumentar sus inversiones en salud, educación y capacitación de los trabajadores para lograr el mejor éxito en los objetivos perseguidos por los incrementos productivos de los salarios.

$>$ El gobiemo debe estructurar una política del mercado laboral que incorpore el principio de que los aumentos salariales hacen crecer la actividad económica real. Mientras que los empresarios tienen que comprender que los incrementos de productividad que se derivan de los aumentos de los salarios reales elevarán sus utilidades.

$>$ El marco jurídico para la negociación obrero-patronal debe incluir reglas que hagan posible que los aumentos de los salarios que se justifiquen como incrementos salariales productivos se convierta en un argumento legal fuerte para elevar los salarios. Este incremento es sobre el salario que ya cubre la fuerza de trabajo. Por tanto, el primer argumento jurídico es el de elevar el salario hasta cubrir el valor de la fuerza de trabajo que, de acuerdo a lo expuesto en este artículo, genera incrementos en la productividad laboral.

\section{Notas}

1. Montesino, Mario, y Góchez, Roberto. Salarios y productividad. Revista Estudios Centroamericanos (ECA); No. 594, Universidad Centroamericana “José Simeón Cañas" UCA; San Salvador, octubre de 1995.

2. Montesino, M. Efecto de la dinámica salarios-productividad en el desarrollo económico. Caso El Salvador (1974-1995). Tesis para optar al grado de Master en economía y desarrollo. Postgrado Centroamericano de Economía y Desarrollo. Tegucigalpa. Honduras. 1997.

3. Marshall, A. Principios de economía. Aguilar, Madrid, cuarta cdición. 1963. P. 165.

4. Marshall, A. Op. Cit. P. 463.

5. Marshall, A. Op. Cit. P. 167-168.

6. “... el capital en sí mismo no es más que la personificación del trabajo cn unión de la espera" Marshall, A. Op. Cit. P. 445.

7. Para un análisis más detallado, que incluyc un modclo matcmático, ver la tesis antes citada.

8. "El lenguaje de Ricardo cs todavía más descuidado que cl de Adam Smith y Malthus..."

Sin embargo, en rcalidad, no sólo Ricardo cstaba enterado de que cl limitc natural o necesario de los salarios no cslaba fijado por una lcy de hicro, sino que se detcrmina por las condiciones locales y las costumbres de cada lugar y ćpoca... (Marshall, A. Op. Cit. P. 418).

9. Marshall de modo similar a los cconomistas clásicos confiaban cn cl adecuado cstablecimiento de los salarios por la competencia en el mercado: "Pero las rentas que producen todos los agentes de producción, tanto humanos como matcriales, y las que parcecn estar llamadas a producir en cl futuro, cjercen una influcncia constante sobre aquellas personas por cuya acción son detcrminadas las oferlas futuras de dichos agentes. Existe una tendencia constante hacia una posición de cquilibrio normal, en la que la oferta de cada uno de csos agentes debe guardar tal relación 
con la demanda de sus servicios que los que han proporcionado la oferta obtengan una remuneración suficiente a sus esfuerzos y sacrificios. Si las condiciones económicas del pais permanecieran estacionarias durante un tiempo suficientemente largo, esta tendencia se realizaría con un ajuste tal de la oferta a la demanda que tanto las máquinas como los seres humanos guardarian generalmente una cantidad que correspondería con bastante exactitud a su coste de manutención y enseñanza, incluyendo en éste, tanto las cosas de necesidad convencional como las estrictamente necesarias." (Marshall, A. Op. Cit. P. 474)

10. Después de mencionar los breves pero importantes aportes de Smith, Ricardo, Mill y Malthus en lo relativo a esta teoría resume de la siguiente forma el estado de la misma en aquel momento: "Pero fue sólo en la última generación cuando se inició un estudio detenido de los efectos que ejercen los salarios elevados sobre el incremento de la eficiencia, no sólo de los que lo perciben, sino también de sus hijos y de sus nietos. En este asunto iniciaron la marcha Walker y otros economistas norteamericanos, y la aplicación del método comparativo de estudio de los problemas industriales de diferentes paises del viejo y nuevo mundo está llamando cada dia más la atención sobre el hecho de que la mano de obra bien pagada es gencralmentc eficiente $y$, por tanto, que no resulta cara, hecho que, aunque es más promctedor que cualquier otro para el futuro de la raza humana, ejerce una influencia muy complicada sobre la teoria de la distribución". (Marshall, A. Op. Cit. 419-420).

11. "En la mayor parte del mundo, los salarios están regidos por la llamada ley de hierro o de bronce, que los mantiene muy cerca de lo estrictamente necesario para la existencia de una clase trabajadora más bien ineficiente". (Marshall, A. Op. Cit. P. 436).

12. “... cuando se utiliza capital fijo costoso, sería más ventajoso para el patrono aumentar los salarios periódicos de los trabajadores más eficientes de un modo más que proporcional a su eficiencia..." En nota a pie de página Marshall agrcga: “... Si hubiese dedicado [se refiere a Ricardo] cuidadosa atención al aumento en la productividad del trabajo que resulta de una mejora en las condiciones del trabajador, los adelantos de la ciencia cconómica y el aumento del biencstar real del país scrian, con toda probabilidad, mucho mayores de lo que cn realidad son..." (Marshall, A. Op. Cit. P. 452-453).

13. Diercksens, Wim, Mercado de trabajo y política económica en Centro América. Guaymuras, Departamento Ecuménico de Investigación (DEJ), San José, Costa Rica, 1990.

14. Esto puede constatarse en la tesis que resume este artículo.

15. Marx, Carlos. El capital (tres tomos) Editorial librerías Allende. México. 1980. P. 500. Ver también Rumiántsev, Economía Política: Capitalismo. Progreso. Moscú. 1980.

16. Aguilar G., Victor. Et al. Capacidad redistributiva de los salarios mínimos y estructura salarial en el sector agropecuario. Tesis de graduación. Universidad Centroamericana “José Simeón Cañas” (UCA), San Salvador, El Salvador, 1993.

* Lo que puede esperarse, en rcalidad, es que aumenten las condicioncs tccnológicas, la relación capital-trabajo y la productividad en las otras ramas.

17. El tst está conformado por 22 preguntas accrea del padecimicnto o no por partc del trabajador de una serie de sufrimientos psíquico-físicos. Estc tipo de sufrimicntos, comprende tanto no sólo las enfermedades que la psiquiatria reconoce como tales 
(la psicosis, la neurosis, etc.), así como psicosomáticas (infarto del miocardio, úlceras digestivas, etc.), sino también toda una serie de sufrimientos que van desde la fatiga a la depresión, pasando por perturbaciones inespecíficas que se producen o se agravan en relación con situaciones de tensión psicosocial en el trabajo (Arriola, J.; 1993: 84).

18. Podría pensarse que esta situación que se presenta en el cuadro 7 responde a una relación espuria pues el deterioro de salud y la productividad podrían estar respondiendo a las condiciones de trabajo, es obvio que tal aseveración no puede descartarse (Arriola además lo demuestra en su investigación); sin embargo, cuando se analizan las condiciones de trabajo se puede verificar que no explican del todo el deterioro de salud (y por tanto el comportamiento de la productividad), lo cual da lugar a que la hipótesis que se viene sosteniendo se mantenga firme. En el cuadro que se muestra a continuación aparecen las condiciones de trabajo para las mismas empresas analizadas en el cuadro 7. Tales condiciones de trabajo están clasificadas en duras (CD), medias (CM) y suaves (CS), las cantidades que ahí aparecen corresponden a los porcentajes de los encuestados que dieron su opinión accrca de las condiciones de trabajo:

\section{Cuadro}

Condiciones de trabajo en la zona franca de san bartolo

\begin{tabular}{llll}
\hline Empresas & CD \% & CM\% & CS\% \\
\hline CORPAK & 75 & 25 & 0 \\
PRIMO & 40 & 52 & 8 \\
AVX & 43 & 43 & 14 \\
\hline
\end{tabular}

Fuente: Arriola, J; ibid.

19. "En el umbral del nuevo siglo, El Salvador se encuentra en un período de crecimiento cercano a cero, y la economía no logra despegar. Es decir que el país ya no puede conseguir las altas tasas de crecimiento tan urgentes para reducir la pobreza y entrar en una etapa de desarrollo sostenible, sin que se hagan importantes transformaciones en la estructura de relaciones económicas y socialcs" (Análisis de Coyuntura, Revista de Estudios Centroamericanos (ECA). Universidad Centroamericana "José Simeón Cañas" (UCA). San Salvador. Febrero-marzo. 2000). 